\title{
O fundacionalismo de Thomas Reid
}

\author{
The foundationalism of Thomas Reid
}

\author{
Vinícius França Freitas* \\ ffvinicius@yahoo.com.br \\ (Universidade Federal de Minas Gerais, Minas Gerais, Brasil)
}

\begin{abstract}
Resumo: 0 objetivo do artigo é discutir em que medida Thomas Reid está comprometido com uma teoria fundacionalista da justificação epistêmica. Para tal, apresentam-se duas discussões. Em primeiro lugar, argumentase que apesar de ser um fundacionalista em geral, Reid não o é em relação a todos os âmbitos do conhecimento - como é o caso da política. Para compreender essa hipótese, distingue-se sua concepção axiomática de ciência de sua visão fundacionalista da estrutura do conhecimento. Em segundo lugar, apresentam-se objeções às interpretações que pretendem que Reid é um antifundacionalista, um coerentista, ou um fundarentista.
\end{abstract}

Palavras-chave: epistemologia; filosofia da ciência; fundacionalismo; Thomas Reid.

\begin{abstract}
The paper aims to discuss in what measure Thomas Reid is committed to a foundationalist theory of epistemic justification. Two discussions are presented. First, it is argued that Reid is in general a foundationalist, but not in all fields of knowledge - this is the case of politics. To understand this hypothesis, it is presented a distinction between Reid's axiomatic conception of science and his foundationalist view of the structure of knowledge. Secondly, the paper presents some objections to those interpretations which intend to hold that Reid is an anti-foundationalist, a coherentist, or a foundherentist.
\end{abstract}

Keywords: epistemology; philosophy of science; foundationalism; Thomas Reid.

DOI: http://dx.doi.org/10.11606/issn.2318-9800.v26i1p13-32

O artigo empreende a discussão de um ponto específico do pensamento de Thomas Reid (1710-1796), a saber, sua compreensão fundacionalista do modo como se estrutura o conhecimento humano. Tenho dois objetivos ao empreender essa discussão. Na primeira seção, pretendo defender que Reid é, "em geral", um fundacionalista. Autores como, por exemplo, Philip de Bary (2002) e John Greco (2004) argumentam em favor dessa possibilidade de interpretação. Contudo, diferentemente de ambos, defendo que Reid não é fundacionalista em relação a

\footnotetext{
* Residente pós-doutoral (PNPD / CAPES) na Universidade Federal de Minas Gerais. O presente trabalho foi realizado com apoio da Coordenação de Aperfeiçoamento de Pessoal de Nível Superior - Brasil (CAPES). Agradeço a Carlota Salgadinho Ferreira pelos valiosos comentários à primeira versão desse trabalho.
} 
todos os campos do saber. Por exemplo, o filósofo apresenta compromissos com essa teoria da justificação epistêmica em relação ao conhecimento da mente humana (em filosofia da mente) e ao conhecimento moral (em filosofia moral), mas não em relação ao conhecimento político. Para defender minha hipótese, argumento que é preciso separar entre o que Reid diz em sua filosofia da ciência, mais especificamente, sua compreensão axiomática de ciência, e o que o autor diz em sua epistemologia, mais especificamente, sua compreensão fundacionalista da estrutura do conhecimento humano. Apesar de o filósofo compreender a ciência política segundo um modelo axiomático de ciência, ele não argumenta no sentido de mostrar que as principais teses de uma posição fundacionalistas estão presentes nesse campo do conhecimento. Na segunda seção, pretendo questionar três interpretações que sugerem que Reid não é fundacionalista, a saber, as interpretações antifundacionalista (de Nicholas Wolterstorff), coerentista (de Keith Lehrer e John-Cristian Smith) e fundarentista (de Gregory Poore).

Antes de me deter sobre essas discussões, esclareço que o artigo é desenvolvido a partir de passagens de Uma investigação sobre a mente humana a partir dos princípios do senso comum (1997), ${ }^{1}$ dos Ensaios sobre os poderes intelectuais do homem (2002), ${ }^{2}$ dos Ensaios sobre os poderes ativos do homem (2010) ${ }^{3}$ e, por fim, da principal fonte do pensamento político de Reid, o conjunto de manuscritos sobre questões sociais e políticas reunidos em Thomas Reid sobre sociedade e política (2015). Tendo em vista compreender o pensamento político reidiano, sua compreensão da fundamentação da ciência política, do papel do cientista político e das fontes do conhecimento político, é preciso considerar sobretudo os manuscritos dos "Cursos de política" ministrados na Universidade de Glasgow entre os anos de 1764 e 1780.

\section{Compreendendo a extensão dos compromissos fundacionalistas de Reid}

Do ponto de vista da filosofia da ciência de Reid, todo conhecimento que se pretende científico deve ser construído segundo um modelo "axiomático" de ciência, tal qual aquele que, a seu ver, Euclides propõe no âmbito das matemáticas: ${ }^{4}$

\footnotetext{
1 Publicada originalmente em 1764. Doravante, apenas Investigação.

2 Publicada originalmente em 1785. Doravante, apenas Poderes intelectuais.

3 Publicada originalmente em 1788. Doravante, apenas Poderes ativos.

4 Sobre a contribuição de Euclides à matemática, Reid afirma: "supor que um sistema tão perfeito como aquele dos 'Elementos' de Euclides foi produzido por um homem apenas, sem nenhum material ou modelo precedente, seria supor que Euclides fosse mais de um homem. Tanto quanto a fraqueza do entendimento humano permite, atribuímo-lo a ele, se supormos que as invenções em geometria, feitas em um intervalo dos tempos anteriores, foram por ele não apenas levadas mais longe mas também digeridas em um sistema tão admirável que seu trabalho obscureceu tudo o que veio antes, fazendo com que tudo fosse esquecido e perdido" (Reid, 2002, pp.512-513).
} 
Nas matemáticas, eles [os fundamentos] foram estabelecidos desde que temos livros. É somente nessa ciência que, por mais de dois mil anos desde que começou a ser cultivada, não encontramos facções, nem sistemas contrários, e dificilmente alguma disputa, ou, se há disputa, elas se encerraram tão logo as animosidades entre as partes se afastaram, nunca mais sendo revividas. A ciência, uma vez estabelecida sobre o fundamento de alguns poucos axiomas e definições, como sobre uma rocha, desenvolveu-se de século a século, de modo a se tornar a mais sublime e sólida fábrica de que a razão humana pode se orgulhar (Reid, 2002, p.457).

O conhecimento científico deve começar pelo estabelecimento de um conjunto de axiomas (particulares àquele campo do saber) a partir dos quais os raciocínios são desenvolvidos e sobre os quais todo o conhecimento (naquele campo particular de saber) é erigido. Como sugerem Haakonssen e Wood na introdução de Thomas Reid sobre Sociedade e Política (2015): “ele [Reid] argumenta que a característica que torna os esforços intelectuais disciplinas filosóficas, ou 'ciências', é uma dependência autoconsciente de um conjunto comum de 'axiomas ou noções comuns' na argumentação" (Haakonssen \& Wood, 2015, p.XLIV).

Em defesa desse modelo científico, Reid aponta o caso de sua aplicação na filosofia natural. Os filósofos da natureza, ao determinarem os axiomas desse campo do conhecimento, trazem ganhos inestimáveis para sua ciência nos séculos XVI e XVII:

Lord Bacon primeiro delineou o único fundamento sólido sobre o qual a filosofia natural pode ser construída. Sir Isaac Newton reduziu os princípios estabelecidos por Bacon a três ou quatro axiomas que ele chamou regulae philosophandi. A partir desses, junto com fenômenos observados pelos sentidos, que ele também estabelece como um princípio primeiro, Newton deduz, mediante um raciocínio estrito, as proposições contidas no terceiro livro de seus Princípios e em sua Ótica. Por esses meios ele erigiu uma fábrica naqueles dois ramos da filosofia natural que não está sujeita a ser sacudida pela disputa duvidosa, permanecendo imóvel (Reid, 2002, p.457).

O modelo axiomático permite o progresso da matemática e da filosofia natural ao eliminar todos os sofismas e opiniões contraditórios do debate, conferindo-lhes estabilidade. O modelo axiomático as traz para um "estado de maturidade". A noção de maturidade de um saber, para Reid, envolve principalmente a noção de "estabilidade" do conhecimento. Uma ciência madura é aquela cujas conclusões não são alvo de infindáveis disputas, tampouco são objeto de dúvidas frequentes. E, mais importante, o seu progresso jamais implicará a destruição de todo aquele saber já construído, de modo que ele sempre será acrescido e nunca diminuído:

A maturidade de uma ciência pode ser julgada a partir disso: quando ela contém um sistema de princípios e conclusões extraídas a partir deles que estão tão firmemente estabelecidas que, entre homens pensantes e inteligentes, não restam dúvidas ou disputas sobre elas. Assim, aqueles que vierem depois podem erigir uma superestrutura mais elevada, não devendo ser capazes de derrubar o que já está construído para começar sobre um novo fundamento (Reid, 2002, p.62). 
Para além da compreensão do modelo de ciência a ser seguido nas investigações filosóficas, Reid também apresenta, do ponto de vista de sua epistemologia, uma compreensão fundacionalista da estrutura do conhecimento. 0 fundacionalismo é uma teoria da justificação epistêmica. De modo conciso, uma teoria da justificação epistêmica é uma teoria filosófica que se propõe a explicar, a partir da pressuposição que os seres humanos não possuem a capacidade de alcançar a verdade de modo "imediato" e "não problemático", ${ }^{5}$ em que medida uma crença pode ser assumida legitimamente pelo indivíduo como crença verdadeira, de que modo ele estaria justificado em assumir essa crença como conhecimento. Por isso, uma teoria da justificação epistêmica pode ser entendida como uma tentativa de explicar como os indivíduos podem reconhecer que suas crenças alcançam a verdade. A justificação epistêmica é oferecida, pode-se dizer, em termos de garantias, provas ou indícios de que determinada crença pode conduzir à verdade. Ao indicar os meios adequados ao objetivo de alcançar a verdade e evitar o erro, a justificação epistêmica de uma crença autoriza a dizer legitimamente "eu sei que p". Uma teoria fundacionalista é uma teoria desse tipo. Michael DePaul apresenta a seguinte compreensão de uma teoria fundacionalista:

Fundacionalistas acerca de alguma propriedade epistêmica defendem que as crenças que possuem esta propriedade são estruturadas como blocos em um edifício. Isto é, fundacionalistas acerca da justificação reconhecem que muitas de nossas crenças dependem, no tocante à sua justificação, de outras crenças justificadas. Contudo, eles também insistem que algumas de nossas crenças justificadas não dependem, no que diz respeito à justificação, de outra crença justificada. Estas crenças são "básicas" ou "fundacionais". Finalmente, tais fundacionalistas defendem que cada uma de nossas crenças justificadas é básica ou parte da superestrutura, com todas as crenças da superestrutura, justificada eventualmente por uma ou mais crenças básicas (DePaul, 2011, p.236).

Um ponto importante em uma teoria fundacionalista da justificação epistêmica é a distinção entre "crenças básicas" ou "fundacionais" e "crenças não-básicas" ou "não-fundacionais". Um fundacionalista epistêmico supõe que crenças do segundo tipo estão justificadas na medida em que se apoiam sobre crenças do primeiro tipo, que estão justificadas independentemente de outras crenças. Crenças básicas ou fundacionais dispõem de determinada "propriedade epistêmica" que permite assumi-las como justificadas por si mesmas, constituindo o fundamento de uma

\footnotetext{
5 Penso aqui, por exemplo, na explicação de Laurence Bonjour (1985) de uma teoria da justificação epistêmica: "o que nos faz seres cognitivos de qualquer modo é a nossa capacidade de acreditar, e o objetivo de nossos esforços distintivamente cognitivos é a 'verdade': queremos que nossas crenças descrevam correta e acuradamente o mundo. Se a verdade fosse acessível de algum modo imediato e não problemático (como o é para Deus, em algumas explicações), de tal maneira que alguém pudesse em todos os casos optar por acreditar na verdade, então o conceito de justificação seria de pouca importância e não desempenharia um papel independente na cognição" (Bonjour, 1985, p.07).
} 
superestrutura de conhecimento que será erigida sobre elas. Portanto, uma teoria fundacionalista da justificação epistêmica possui duas grandes premissas: ${ }^{6}$

(1) Existe um conjunto de crenças que são autoevidentes ou imediatamente justificadas, as “crenças básicas” / "fundacionais";

(2) Existe um conjunto de crenças que são justificadas em virtude de suas relações com outras crenças autoevidentes ou imediatamente justificadas, isto é, um conjunto de crenças que dependem de outras crenças para serem justificadas, as "crenças não-básicas” / “não-fundacionais”.

Crenças básicas, justificadas por si mesmas ou imediatamente justificadas, servem como fundamento sobre o qual as crenças não-básicas são erigidas, a "superestrutura do conhecimento". Como ilustra a "metáfora do edifício", 7 em uma teoria fundacionalista, crenças básicas / fundacionais são os blocos que não dependem de nenhum outro bloco para estarem firmemente assentados e que suportam todo o peso do edifício, a superestrutura do conhecimento, que é construída sobre elas.

Se estou certo em minha compreensão - e na segunda seção pretendo defendê-la das interpretações que the vão de encontro -, a distinção de Reid entre "proposições intuitivas" e "proposições baseadas em argumento" e sua compreensão da autoevidência dos princípios primeiros é o que o torna um fundacionalista. Reid não apenas reconhece o problema do regresso epistêmico, resultante da busca pelo fundamento do conhecimento, ${ }^{8}$ como também reconhece a necessidade de distinção entre dois tipos de crenças. São as proposições intuitivas, as crenças básicas / fundacionais, que previnem o regresso ad infinitum na investigação filosófica:

6 Ver também Roderick Chisholm (1964, p.261) e Laurence Bonjour (1985, pp.16-17).

7 DePaul diz, acerca dessa metáfora: “Em um edifício construído com blocos, muitos blocos são suportados por outros blocos, mas alguns não são suportados por nenhum outro bloco. Blocos que não são suportados por outros blocos formam a fundação, suportando o restante da estrutura, isto é, toda a superestrutura de blocos. Cada bloco na estrutura ou é parte da fundação ou parte da superestrutura. Portanto, o peso de toda a superestrutura de blocos é eventualmente carregado por um ou mais blocos fundacionais" (DePaul, 2011, p.236).

8 Uma teoria da justificação epistêmica pode ser compreendida a partir da discussão do problema ou argumento do "regresso epistêmico". A busca por razões que justifiquem as crenças implica uma regressão que, se não interrompida, pode permanecer até o infinito. Com efeito, verifica-se que a crença $B$ justifica a crença A; a crença $C$, por sua vez, justifica a crença $B$, e a crença $D$ justifica a crença $C$. No caso de uma cadeia infinita de crenças justificantes, torna-se impossível apontar em que momento dessa busca pela justificação a afirmação do conhecimento é estabelecida. Em vista dessa possibilidade de regressão ad infinitum, o filósofo sugere (ao menos em algumas das formas de ceticismo) que nenhuma de nossas crenças está justificada em último caso e que, portanto, não é possível conhecer. Um fundacionalista admite que algumas crenças estão justificadas mesmo quando não existe nenhuma outra crença que as justifique. Ver James Van Cleve (2005, p.168). 
Quando examinamos, mediante análise, a evidência de qualquer proposição, descobrimos sua autoevidência ou descobrimos que ela se apoia em uma ou mais proposições que a fundamentam. A mesma coisa pode ser dita das proposições que a fundamentam, e daquelas que fundamentam essas, regredindo tanto quanto pudermos. Mas não podemos seguir esse trajeto ao infinito. Portanto, onde essa análise deve terminar? É evidente que ela deve terminar somente quando encontramos proposições que fundamentam tudo aquilo que é construído sobre elas, mas elas mesmas não são fundamentadas por nada (Reid, 2002, p.455).

Proposições intuitivas são o fundamento do qual proposições baseadas em argumentos dependem. 0 que thes caracteriza como crenças autoevidentes é o assentimento natural e imediato que se lhes segue tão logo são compreendidas pelo ser humano:

O juízo se segue necessariamente à sua apreensão, [...]. Não há busca pela evidência nem pesagem de argumentos: a proposição não é deduzida ou inferida de outra, visto que ela possui a luz da verdade em si mesma, de modo que não há ocasião para tomála emprestada de outra proposição (Reid, 2002, p.452).

O juízo sobre a verdade ou falsidade do que é afirmado, nesses casos, não exige nenhuma formulação de argumento, tampouco a apresentação de alguma razão para que a mente possa julgar sobre a verdade e a falsidade. Estas proposições carregam a luz da verdade em si, são autoevidentes, e a mente lhes assente de modo irresistível e imediato. Reid afirma sobre as proposições baseadas em argumentos, por sua vez:

Algumas [proposições] são de tal maneira que um homem de entendimento amadurecido pode apreendê-las distintamente e entender perfeitamente seu significado sem se encontrar sob a necessidade de acreditar que elas são verdadeiras ou falsas, prováveis ou improváveis. O juízo permanece em suspenso, até que ele seja inclinado, por razões ou argumentos, para um lado ou outro (Reid, 2002, p.452).

Proposições baseadas em argumentos são aquelas cujo juízo sobre a verdade ou falsidade do que ela afirma ou nega é mediato, visto a exigência de consideração sobre a evidência que lhe é própria. 0 juízo, nesses casos, ocorre apenas depois da formulação de algum argumento ou da apresentação de alguma razão que faça com que a mente julgue e esteja convicta da verdade ou falsidade.

Como dito pouco acima, sobre as premissas encontradas em uma teoria fundacionalista, na filosofia de Reid:

(1) Existe uma classe de crenças que são autoevidentes ou justificadas imediatamente, isto é, existem crenças cuja justificação não depende de nenhuma outra crença;

(2) Existe outra classe de crenças que são justificadas em virtude de suas relações com aquelas crenças autoevidentes ou justificadas imediatamente, isto é, crenças cuja justificação depende de outras crenças. 
Proposições intuitivas, crenças cuja convicção se segue imediatamente após sua compreensão, são os princípios primeiros sobre os quais o conhecimento humano deve se assentar: "quando são utilizadas em matérias de ciência, são comumente chamadas 'axiomas', e em qualquer outra ocasião em que são usadas, são chamadas 'princípios primeiros', 'princípios do senso comum', 'noções comuns', 'verdades autoevidentes'” (Reid, 2002, p.452). Os princípios autoevidentes sobre os quais o conhecimento é construído - em alguns campos do saber - são devidos ao senso comum, isto é, à constituição original da mente humana: ${ }^{9}$

Se existem certos princípios, como eu penso que os haja, aos quais a própria constituição de nossa natureza nos leva a acreditar e que nos vemos sob a necessidade de tomar como certos nos interesses comuns da vida, sem sermos capazes de dar-lhes uma razão, esses são o que chamamos princípios do senso comum (Reid, 1997, p.33, grifos meus).

Doravante, discuto a relação entre a compreensão reidiana do modelo axiomático de ciência e sua visão fundacionalista do conhecimento. Observo que a interpretação de que Reid é um fundacionalista não é nova na literatura secundária. De Bary (2002, pp.49-63) e Greco (2004, pp.148-151), por exemplo, já a defenderam. 0 que minha interpretação pretende é estabelecer a necessidade de se distinguir a visão axiomática de ciência de Reid de sua visão fundacionalista, distinção ausente na interpretação de ambos os autores. Acredito que o ganho dessa distinção é permitir a compreensão de que, apesar de o filósofo assumir o modelo axiomático como paradigma de conhecimento científico, ele não é fundacionalista em todos os campos do conhecimento. Uso, como exemplo, os casos da filosofia da mente (i), moral (ii) e política (iii). Apesar de compreender esses três campos do saber a partir do modelo axiomático, ele assume compromissos fundacionalistas apenas no que diz respeito à filosofia da mente e à moral.

(i) Reid é fundacionalista em relação ao conhecimento dos fenômenos mentais, a filosofia da mente. Os princípios primeiros desse campo do saber são os princípios primeiros do senso comum, os princípios autoevidentes, justificados imediatamente. Sobre eles, ergue-se toda a superestrutura do conhecimento sobre a mente: "a Filosofia [...] não possui outra raiz senão os princípios do Senso Comum [os princípios primeiros autoevidentes, justificados imediatamente]. Ela cresce e deles extrai seu alimento. Separada de suas raízes, sua honra murcha, sua seiva seca, ela morre e apodrece" (Reid, 1997, p.19). E, em outra passagem, em que o filósofo discute a fundamentação da filosofia da mente:

9 Para uma discussão mais detalhada da noção de "senso comum" em Reid, ver "A noção de senso comum em Thomas Reid” (Freitas, 2020). 
Reconheço que se fossemos nos manter sobre aqueles juízos da natureza [as crenças devidas à constituição original da mente humana] de que falamos agora, sem construir outros sobre eles, eles não autorizariam a denominação de seres razoáveis. Contudo, eles não devem ser desprezados, pois eles são o fundamento sobre o qual a grande superestrutura do conhecimento humano deve ser erguida (Reid, 2002, p.412).

Nesse campo do conhecimento, é um princípio primeiro do senso comum a crenças sobre a existência dos objetos do mundo externo: "todas aquelas que percebemos distintamente pelos sentidos realmente existem e são aquilo que percebemos que elas são” (Reid, 2002, p.476). Para Reid, existe, na filosofia da mente, uma classe de crenças que são autoevidentes ou justificadas imediatamente e existe também outra classe de crenças que são justificadas em virtude de suas relações com aquelas crenças autoevidentes ou justificadas imediatamente.

(ii) Reid é fundacionalista em relação ao conhecimento dos fenômenos morais, a filosofia moral. Crenças morais não-fundacionais são justificadas em virtude de suas relações com crenças morais fundacionais, os princípios primeiros do senso comum, crenças que são justificadas independentemente de qualquer outra crença moral. A superestrutura do conhecimento sobre agir de acordo com a obrigação moral depende de crenças autoevidentes: “deve existir, portanto, na moral, como em todas as outras ciências, princípios primeiros autoevidentes sobre os quais todo raciocínio é fundado e sobre os quais, em último caso, ele permanece” (Reid, 2010, p.177). As crenças morais imediatas e irresistíveis são os princípios primeiros autoevidentes do conhecimento moral, de modo que os raciocínios morais são desenvolvidos a partir delas. Desse tipo é, por exemplo, o seguinte princípio primeiro da moral: “o que não é em nenhum grau voluntário não pode merecer nem aprovação nem desaprovação moral” (Reid, 2010, p.271). Para Reid, existe, na moral, uma classe de crenças que são autoevidentes ou justificadas imediatamente e outra classe de crenças que são justificadas em virtude de suas relações com aquelas crenças autoevidentes ou justificadas imediatamente.

(iii) Reid não é fundacionalista em relação ao conhecimento político. 0 filósofo vê a política de acordo com aquela concepção axiomática de ciência sem, contudo, defender aquelas duas principais premissas presentes em uma teoria da justificação epistêmica do tipo fundacionalista. 0 ponto de partida da ciência política é o estabelecimento dos axiomas a partir dos quais os raciocínios do cientista político devem ser desenvolvidos: "se a política pode ser completamente reduzida a uma ciência, e duvido que não o possa ser, devem existir certos princípios a partir dos quais nossos raciocínios em política são deduzidos” (Reid, 2015, pp.26-27). Reid aponta sobre os princípios primeiros da política: 
é evidente que os princípios primeiros do raciocínio político em geral devem ser desse tipo, a saber, que tal é a natureza da humanidade, que os homens colocados em tais circunstâncias em geral agirão dessa maneira. Se algum princípio desse tipo puder ser estabelecido a partir do nosso conhecimento da natureza humana, ou da experiência, tais princípios serão o fundamento de todo raciocínio político e as conclusões extraídas justamente desses princípios formarão a ciência da política (Reid, 2015, p.27).

Discuti minha compreensão da ciência política de Reid em outro trabalho (Freitas, 2018). De modo conciso, os princípios primeiros de um sistema de moralidade, diz o filósofo, são oferecidos pela consciência moral dos seres humanos, aquele poder de julgar o certo e o errado nas ações segundo o dever. Em outras palavras, o conhecimento moral está fundado sobre os princípios primeiros do senso comum. Os princípios da política são encontrados em outra fonte. A fonte da qual os princípios primeiros ou axiomas da ciência política são extraídos é o "conhecimento da humanidade", isto é, o conhecimento dos princípios de ação e o conhecimento da inclinação geral da conduta dos indivíduos que se reúnem em sociedade sob um governo político. ${ }^{10} \mathrm{O}$ conhecimento "do temperamento e da disposição, dos princípios de ação e da tendência geral de conduta que é comum a toda uma espécie" (2010, p.27). Este conhecimento, acredita Reid, permite saber em alguma medida de que modo os indivíduos agem em certas circunstâncias, que ações podem ser esperadas quando certos motivos concorrem para que elas sejam realizadas. Em uma passagem bastante esclarecedora dos Poderes ativos, o filósofo observa do mesmo modo, sobre esta fonte de princípios primeiros:

A ciência da política toma emprestado seus princípios do que conhecemos por "experiência do caráter e conduta dos homens". Consideramos não o que ele deve ser, mas o que ele é, e, portanto, concluímos que papel ele desempenhará em diferentes situações e circunstâncias. A partir de tais princípios, raciocinamos sobre as causas e efeitos de diferentes formas de governo, leis, costumes e maneiras. Se o homem fosse ou mais perfeito ou mais imperfeito, uma criatura melhor ou pior do que ele é, a política seria uma ciência diferente do que ela é (Reid, 2010, p.179).

Os axiomas da política são crenças sobre como um corpo de indivíduos, em geral, age quando colocado em determinadas situações. Diferentemente dos princípios primeiros do senso comum, os axiomas da política não são princípios devidos à constituição original da mente humana. Eles não são autoevidentes ou justificados imediatamente. Eles dependem de um conhecimento prévio da natureza humana, de uma experiência acerca de como os seres humanos agem em sociedade para serem formulados. Todos aqueles que experienciam viver entre indivíduos em sociedade são capazes de formar crenças desse tipo, como aponta Reid nos Poderes ativos:

10 "É fácil mostrar que os princípios primeiros da política, sobre os quais todos os raciocínios políticos são baseados, devem ser tomados do conhecimento da humanidade. Não quero dizer por conhecimento da humanidade o conhecimento do temperamento peculiar e dos talentos individuais, mas o conhecimento do temperamento e da disposição, dos princípios de ação e da tendência geral de conduta que é comum a toda uma espécie” (Reid, 2015, p.27). 
Um homem de sagacidade que teve oportunidade de lidar com questões de interesse, com uma grande variedade de pessoas de diferentes idades, sexos, classes e profissões, aprende a julgar o que pode se esperar dos homens em dadas circunstâncias e como eles podem mais efetivamente ser induzidos a desempenhar o papel que ele deseja (Reid, 2010, p.75).

Viver em sociedade, no entanto, não é suficiente. Para Reid, o cientista político deve ir além desse conhecimento comum da natureza humana. Ele precisa realizar um trabalho mais rigoroso de descoberta e classificação dos princípios de ação:

O homem do mundo conjectura, talvez com grande probabilidade, sobre como um homem agirá em certas circunstâncias, sendo isto tudo o que ele deseja saber. Entrar em detalhes acerca dos diversos princípios que influenciam as ações dos homens, dando-lhes nomes distintos, definindo-os e verificando suas diferentes competências, esse é o trabalho de um filósofo (Reid, 2010, pp.75-76).

0 texto dos "Cursos de política" não é sistemático sobre o processo de descoberta dos axiomas da política. No entanto, a meu ver, o processo pode assim ser descrito. Inicialmente, à luz da observação da conduta dos seres humanos em sociedade (a experiência que o cientista político tem de como os seres humanos atuam em geral), o cientista político observa que os seres humanos agem segundo o seu dever em relação aos outros em sociedade. A partir do estudo filosófico dos princípios de ação na mente humana, ele descobre que há um princípio moral que geralmente motiva as ações dos indivíduos. ${ }^{11}$ Descobre-se que os seres humanos em geral se sentem obrigados a agir corretamente do ponto de vista moral. ${ }^{12} \mathrm{Na}$ sequência, ainda a partir de sua experiência de viver em sociedade, o cientista observa que os indivíduos agem de acordo com esse princípio moral na maior parte dos casos, exceto quando eles estão sujeitos a uma forte tentação de não o seguir. 0 indivíduo que trai um amigo fá-lo em virtude de alguma razão que o motiva a agir contrariamente ao seu dever - uma forte paixão pode estar afetando-o, por exemplo. Observando a regularidade desse tipo de comportamento nas sociedades, formulase um axioma do conhecimento político: "os homens serão em geral honestos e verdadeiros quando não houver uma tentação que os faça agir de outra maneira" (Reid, 2015, pp.30-32).

11 Isto é: "Portanto, assumo como certo que cada homem de real valor sente uma repugnância de certas ações, visto que elas são em si mesmas infames, e sente-se obrigado a outras ações, uma vez que elas são em si mesmas o que a honra exige. E isto é independente de qualquer consideração pelo interesse ou reputação" (Reid, 2010, p.170).

12 Esse é o princípio do dever, a obrigação moral imediata do indivíduo: "o princípio da honra, que é reconhecido por todos os homens que pretendem ao caráter, é somente outro nome para o que chamamos consideração pelo dever, pela retidão, pela propriedade de conduta. É uma obrigação moral que obriga o homem a fazer certas coisas porque elas são certas e não fazer outras tantas porque elas são erradas" (Reid, 2010, p.170). Obrigação moral, princípio moral, princípio da honra, são todos nomes dados ao senso do dever ou princípio racional de ação da consideração pelo dever. 
Um axioma político, portanto, não é autoevidente ou justificado imediatamente à maneira de um princípio primeiro do senso comum. Reid, por essa razão, não seria um fundacionalista no que diz respeito ao conhecimento político. Na filosofia da mente, é um princípio primeiro do conhecimento a crença de que os objetos do mundo externo existem. Isso é autoevidente, justificado imediatamente. 0 filósofo não realiza nenhuma investigação em busca de princípios desse tipo. Essa é uma crença básica a partir da qual o cientista da mente raciocinará. Na ciência política, diferentemente, os axiomas não são do mesmo tipo. Os princípios da política são produzidos por uma mistura de sagacidade natural e experiência do cientista político que vive em sociedade. Eles são observações empíricas sobre como os seres humanos agirão quando colocados em certas circunstâncias, uma crença devida ao conhecimento empírico da conduta humana. A crença de que os indivíduos agirão honestamente quando não houver tentação para agir de outra forma é uma crença formada a partir da experiência do modo como os seres humanos agem em sociedade. Portanto, não é autoevidente, não é imediatamente justificada.

O que torna Reid fundacionalista é sua defesa da existência de uma classe de crenças que são autoevidentes ou justificadas imediatamente, crenças cuja justificação não depende de nenhuma outra crença, e a existência de outra classe de crenças que são justificadas em virtude de suas relações com aquelas crenças autoevidentes ou justificadas imediatamente. Para Reid, existem princípios primeiros que são imediatamente justificados, os princípios primeiros do senso comum, que são o fundamento do conhecimento em alguns campos do saber. Se estou certo em minha interpretação, no entanto, o fundacionalismo reidiano não se estende a todos os âmbitos do conhecimento humano. 0 filósofo não apresenta compromissos fundacionalistas no campo da política, por exemplo.

\section{Contra as interpretações antifundacionalista, coerentista e fundarentista}

O objetivo nessa seção é considerar três interpretações distintas do modo como Reid entende a estrutura do conhecimento, a saber, a antifundacionalista, a coerentista e a fundarentista. Pretendo mostrar as dificuldades de cada uma dessas três formas de entender a filosofia reidiana do conhecimento:

1. Nicholas Wolterstorff (2001) acredita que Reid é na verdade um antifundacionalista. A seu ver, o filósofo não teria desenvolvido uma teoria da justificação epistêmica, de modo que ele seria "um realista metafísico que também é, a sua maneira, um antifundacionalista" (Wolterstorff, 2001, p.X). Reid teria abandonado o projeto de justificar as crenças do senso comum, diferentemente do que muitos intérpretes estariam tentados a pensar sobre as suas intenções: 
As crenças surgem com uma variedade de méritos e deméritos relevantes à verdade. Elas são garantidas, fiáveis, formadas, autorizadas, justificadas, racionais, casos de conhecimento, aptas à inclusão na ciência, e assim por diante. A epistemologia contemporânea de tradição analítica tem se preocupado, nos anos recentes, com a tentativa de oferecer uma análise de méritos como esses, e critérios para sua aplicação. Uma pessoa treinada nessa tradição estará inclinada naturalmente a extrair de Reid uma teoria da garantia, uma teoria da autorização, uma teoria da justificação, ou o que quer que seja (Wolterstorff, 2001, p.02).

Apesar de todos aqueles indícios de interesse pelo problema filosófico da verdade das crenças humanas, Reid não estaria comprometido com uma teoria fundacionalista do conhecimento.

Uma importante noção para a compreensão dessa interpretação refere-se ao entendimento, segundo Wolterstorff, que Reid teria do ceticismo. 0 "cético (na visão) de Reid" é aquele filósofo que pretende determinar qual deve ser o objetivo da filosofia no tocante à investigação do conhecimento. O cético estabelece que é preciso, de início, abandonar todas as suas crenças mais fundamentais, como, por exemplo, as crenças formadas pela percepção e pela memória. Em seguida, ele deve buscar pelo critério capaz de apontar a veracidade desses juízos e crenças. De acordo com o cético de Reid, o filósofo só está autorizado a retomar suas crenças quando ele encontrar esse critério. Esse modo de proceder é o que Wolterstorff chama de a "imposição" (injunction) do cético. Sobre esse cético (na visão) de Reid, o intérprete afirma:

Ele é um fundacionalista classicamente moderno que recorda Reid de suas obrigações como filósofo. Até agora Reid simplesmente descreveu como se passam as coisas - ou parecem se passar. 0 cético insiste que Reid, no tocante a isso que ele considera, tem uma obrigação de ir além da descrição, na condição de filósofo. Sua obrigação como filósofo é fazer o melhor (ou tentar) para descobrir se aquelas supostas apreensões e supostas crenças são aquilo que elas supõem ser. Ele é obrigado, como filósofo, a reunir um corpo satisfatório de evidências sobre elas. Feito isto, ele é então obrigado a acreditar ou desacreditar de acordo com as demandas do fundacionalismo clássico moderno (Wolterstorff, 2001, p.192).

O cético de Reid, portanto, é aquele filósofo que entende que a filosofia do conhecimento deve justificar os juízos e crenças do ser humano. Reid, em sua perspectiva antifundacionalista, tal como Wolterstorff o entende, limitar-se-ia a descrever os processos mentais que conduzem o ser humano às suas crenças, opondose ao ceticismo justamente nisso que diz respeito à imposição do cético. 0 principal argumento da crítica reidiana ao ceticismo, ao ver de Wolterstorff, é defender que não é possível ir além da descrição das operações da mente na investigação da mente humana, que não é possível determinar-se por aquela imposição do cético:

Muito embora a resposta de Reid ao cético tenha vários componentes distintos, todos esses componentes constituem, no fundo, diferentes facetas de apenas uma 
estratégia. Ao invés de tentar seguir a “imposição" do cético, Reid argumenta que a própria imposição está, de diversas maneiras, séria e irreparavelmente defeituosa (Wolterstorff, 2001, p.192, grifos meus).

É justamente a imposição do cético que Reid atacaria. Os filósofos não têm a obrigação de abandonar suas crenças se elas não são justificadas do ponto de vista da razão, mesmo que o cético diga para fazê-lo. Não está em poder dos seres humanos negar o assentimento às suas crenças fundamentais. O filósofo jamais se determina em sua investigação por um propósito fundacionalista, limitando-se, desse modo, à descrição dos mecanismos mentais do ser humano na percepção, memória e outros poderes intelectuais.

Em resposta a essa interpretação, digo que, na seção anterior, acredito ter reunido evidências textuais suficientes que mostram de que maneira Reid está comprometido não apenas com uma tese sobre a verdade dos princípios primeiros do senso comum como também com uma teoria fundacionalista da justificação epistêmica. A meu ver, a distinção entre proposições intuitivas e proposições baseadas em argumentos e sua visão sobre a autoevidência dos princípios primeiros do conhecimento tornam Reid um filósofo fundacionalista, muito embora não seja em todos os campos do conhecimento. Adiciono a esse argumento que, diferentemente do que Wolterstorff supõe, Reid está realmente interessado pela questão da verdade dos princípios primeiros do senso comum. Reid nota que, ainda que os princípios primeiros do senso comum sejam autoevidentes:

Existem muitas maneiras por meio das quais podemos tornar a evidência de princípios primeiros mais aparente quando eles são colocados em disputa. Contudo, existe uma maneira particular de se lidar com eles que lhes é própria. Sua evidência não é demonstrativa, mas intuitiva. Eles não exigem prova, mas podem ser colocados em uma perspectiva mais apropriada (Reid, 2002, p.41, grifos meus).

Os princípios primeiros do senso comum, as crenças autoevidentes, justificadas imediatamente, não apenas são verdadeiras como podem, por meio de argumentos, ser colocadas em uma posição mais favorável em que sua verdade se torna mais aparente. Esses argumentos devem ser entendidos apenas como "maneiras por meio das quais" sua evidência pode tornar-se mais aparente. Eles são princípios autoevidentes e não dependem de nenhum outro princípio, de modo que esses argumentos não provam a verdade dessas crenças. ${ }^{13}$ Por essa razão, julgo-me autorizado a supor que Reid

13 Cito, por exemplo, o argumento de acordo com o qual seria impossível provar a fiabilidade das faculdades da mente e, por essa razão, os filósofos devem iniciar suas investigações aceitando a verdade de todas as crenças que delas resultam. Segundo Reid, o processo de fornecer a prova da fiabilidade das faculdades mentais implica uma circularidade inevitável no raciocínio. É impossível provar sua fiabilidade sem apelar às próprias faculdades cuja fiabilidade é questionada: "se a honestidade de um homem é colocada em questão, seria ridículo remetermo-nos à palavra do próprio homem, seja ele honesto ou não. Há o mesmo absurdo na tentativa de provar, por qualquer tipo de raciocínio, provável ou demonstrativo, que nossa razão não é falaciosa, uma vez que o 
vai além da descrição psicológica dos processos mentais de formação de crenças. A seu ver, as crenças do senso comum são crenças verdadeiras devidas à constituição original da mente humana.

2. Há autores que entendem Reid como um filósofo coerentista. Uma teoria coerentista da fundamentação epistêmica estabelece, grosso modo, que uma crença pode ser justificada por ser parte de um sistema coerente de crenças, de modo que ela não precisa se apoiar sobre outra crença mais fundamental para estar justificada (cf. Stern, 2004, p.298). Benjamin W. Redekop (2002) não afirma explicitamente que Reid é um coerentista, mas o sugere. ${ }^{14}$ Suspeito que Michel Malherbe (1991) também sugere essa interpretação ao afirmar que a justificação do senso comum está na "contaminação recíproca” de seus princípios, princípios que possuiriam o papel de pressupostos teóricos da investigação (os princípios primeiros a partir dos quais o estudo será empreendido) e de resultados encontrados ao fim da investigação filosófica (os princípios da natureza humana revelados pelo estudo atento das operações mentais). ${ }^{15}$ Outra sugestão aparece em James Van Cleve (2003), autor que afirma a existência de uma "rede de autoevidência" (Web of self-evidence) na filosofia reidiana do conhecimento. ${ }^{16}$ Contudo, Keith Lehrer é quem afirma explicitamente a interpretação coerentista da filosofia reidiana do conhecimento. Em um trabalho publicado conjuntamente com John-Cristian Smith (1985), ambos os autores apontam passagens da Investigação e dos Poderes intelectuais que possibilitariam a compreensão coerentista da teoria dos princípios primeiros. A primeira dessas passagens diz:

próprio ponto em questão é saber se podemos confiar no raciocínio" (Reid, 2002, p.480). Portanto, para Reid, os filósofos devem aceitar a fiabilidade das faculdades da mente e, consequentemente, a verdade das crenças que resultam dessas operações. Para uma discussão mais detalhada dos argumentos de Reid em favor da verdade dos princípios primeiros do senso comum, ver "A resposta de Thomas Reid ao ceticismo" (Freitas, 2020).

14 Ao discutir a validade dos princípios primeiros, Redekop afirma: "como podemos estar certos de que eles são corretos? Princípios primeiros válidos são consistentes com outros princípios primeiros, não levam a conclusões absurdas" (Redekop, 2002, p.43, grifos meus).

15 A expressão "contaminação recíproca" é utilizada por Etienne Brun-Rovet (2002) para se referir à ideia de Malherbe sobre o duplo estatuto dos princípios primeiros do senso comum: "verdades primárias" e "verdades finais" (Brun-Rovet, 2002, p.499).

16 Van Cleve diz: "digamos que uma crença é epistemicamente anterior a outra (ou que aquelas crenças de uma classe são epistemicamente anteriores àquelas crenças de outra) se essa última deriva sua evidência da evidência da primeira, de tal maneira que a última não poderia ser evidente a menos que a primeira já o fosse. Digamos que a crença é autoevidente se ela for evidente, mas não há nada epistemicamente anterior a ela. Poderíamos então dizer que uma teoria da coerência que rejeita a própria ideia de prioridade epistêmica é uma teoria que, ao invés de repudiar a categoria da autoevidência, faz com que cada crença evidente seja autoevidente. Reid, ainda que não vá tão longe, poderia assumir que as crenças particulares e as crenças gerais dependem umas das outras para sua evidência sem com que as crenças, sejam de qual tipo forem, sejam anteriores umas às outras, de modo que particulares e gerais seriam ambas autoevidentes" (Van Cleve, 2003, p.170). 
Existe uma semelhança maior do que se imagina entre o testemunho da natureza dado por nossos sentidos e o testemunho dado pela linguagem. 0 crédito que damos a ambos é, de início, somente efeito do instinto. Quando crescemos e começamos a raciocinar sobre eles, o crédito dado ao testemunho humano é restringido e enfraquecido, pela experiência que temos de seu engano. Mas o crédito dado ao testemunho de nossos sentidos é estabelecido e confirmado pela uniformidade e constância das leis da natureza (Reid, 1997, p.171, grifos meus).

$\mathrm{Na}$ visão dos intérpretes, essa passagem é importante na medida em que sugere que o testemunho dos sentidos pode ser confirmado pela experiência, ou a uniformidade da natureza. Em outras palavras, a coerência entre as crenças perceptivas confirmaria os princípios primeiros sobre a fiabilidade da percepção (Lehrer \& Smith, 1985, p. 26). A segunda passagem, por sua vez, aponta:

Senso comum e razão possuem ambos o mesmo autor, aquele autor Onipotente, em que em todos os outros trabalhos observamos uma consistência, uniformidade e beleza, que encantam e deleitam o entendimento. Deve existir, portanto, alguma ordem e consistência nas faculdades humanas, tanto quanto em outras partes de seu trabalho (Reid, 1997, p.69, grifos meus).

A ordem e consistência das faculdades é o que justificaria a verdade das crenças do senso comum segundo essa passagem. Finalmente, a terceira passagem, a mais forte indicação do coerentismo de Reid segundo Lehrer e Smith (1985, p.37). Reid diz nos Poderes intelectuais: “dificilmente há uma proposição, especialmente essas que podem ser afirmadas como princípios primeiros, que permanece por si mesma e desconectada [de outras proposições]. Ela arrasta muitas outras consigo em uma cadeia que não pode ser quebrada" (Reid, 2002, p.464). Estas três passagens sugeririam, segundo os autores, que Reid de fato mantém um tipo de teoria coerentista de justificação epistêmica. A verdade das crenças do senso comum "é uma consequência da coerência do sistema [das crenças humanas]” (Lehrer \& Smith, 1985, p.37).

Apesar dessas três passagens com teor coerentista, Reid de fato não abandona uma visão fundacionalista em favor da justificação pela coerência do sistema de crenças. Como Robert Stern explica:

Diz-se que o coerentismo se distingue [do fundacionalismo] na medida em que ele dispensa a ideia de crenças básicas e, de outro modo, bloqueia o regresso [epistêmico] apelando ao lugar de uma crença em um sistema para justificá-la: isto permite que a crença seja justificada sem uma base inferencial adicional, sem a crença ser imediatamente justificada, como no quadro fundacionalista (Stern, 2004, p.298).

Como explicar todas as passagens do texto de Reid sobre a autoevidência dos princípios primeiros do senso comum? Seria possível negar que esses princípios primeiros são as crenças básicas sobre as quais toda a superestrutura do conhecimento, como Reid reconhece textualmente, é construída? A verdade dos princípios primeiros depende da posição que esses princípios ocupariam em um sistema doxástico, apesar de tudo 
o que foi dito sobre o seu papel fundamental? A interpretação coerentista parece não se sustentar. Não há, além daquelas três passagens, uma teoria sistematizável na filosofia reidiana que encontra na coerência a garantia da verdade das crenças do senso comum. Os pressupostos fundacionalistas de Reid são deveras extensos para que sejam abandonados em favor de uma interpretação coerentista, uma interpretação que não possui uma base textual que vai além daquelas três passagens pontuais.

Acredito ter mostrado evidência textual de como Reid faz uso de termos muito importantes em teoria fundacionalistas da justificação, como, por exemplo, "fundamento", "superestrutura", "proposições intuitivas" e "princípios autoevidentes" (que entendo como sendo crenças básicas / fundacionais), e "proposições baseadas em argumentos" (que entendo como sendo crenças não-básicas / não-fundacionais). Não apenas o jargão aparece no texto reidiano: a ideia principal de uma teoria fundacionalista está presente nas obras de Reid: existe um conjunto de crenças imediatamente justificadas sobre as quais outras crenças que não são imediatamente justificadas são assentadas. Como mostrado acima, Reid afirma que os princípios primeiros são o fundamento sobre o qual muitos campos do conhecimento são erigidos, como, por exemplo, a filosofia da mente e a moral. Eles são princípios autoevidentes cuja verdade é imediatamente assumida: eles não dependem de nenhuma outra crença para serem verdadeiros, tampouco dependem da coerência do sistema de crenças. A coerência das crenças não é um elemento de sua justificação na filosofia reidiana, nem sequer uma forma de justificação adicional, como é visto a seguir. ${ }^{17}$

3. Apesar do que disse a respeito da possibilidade de uma interpretação coerentista da compreensão reidiana da estrutura do conhecimento, talvez seja possível pensar a possibilidade de uma interpretação que conjugue tanto os aspectos fundacionalistas quanto coerentistas na filosofia de Reid. Apesar de que, à primeira vista, essa possibilidade possa parecer promissora, argumento, na sequência, que o próprio texto reidiano a elimina. De acordo com Gregory Poore (2015), existe uma mistura de fundacionalismo e coerentismo na filosofia de Reid: 18 "argumento que a epistemologia de Reid não é simplesmente fundacionalista, ela contém traços de coerentismo:

17 É preciso esclarecer que Lehrer parece abandonar a interpretação coerentista da filosofia de Reid. Em "Reid on Consciousness", Lehrer a sugere, sem defendê-la sistematicamente (Lehrer, 1986, p.02). No entanto, em sua obra "Thomas Reid" (1989), apesar de uma rápida referência ao valor (do ponto de vista epistêmico) do caráter sistemático dos princípios primeiros, essa interpretação desaparece (Lehrer, 1989, pp.155-156). Há, no entanto, uma sugestão dessa interpretação no artigo "Thomas Reid on Common Sense and Morals" (2013): "as características do sistema [de Reid] exigem elaboração. Primeiramente, permitam-me um comentário sobre o caráter das faculdades e princípios primeiros. As faculdades são capacidades originais da mente que estão, segundo Reid, conectadas como elos em uma corrente" (Lehrer, 2013, p.112). O autor, no entanto, não se detém sobre uma discussão mais aprofundada da questão.

18 Susan Haack (1993) chama essa mistura de "fundarentismo" (foundherentism). Na sequência do artigo, usarei esse termo, ainda que Poore não o utilize. 
[...] ainda que essa justificação impulsionada [boosted justification] não seja, em geral, necessária para o conhecimento, ela é valorosa" (Poore, 2015, p.213). Ele explica sua interpretação em maiores detalhes:

Argumentando que a epistemologia de Reid possui traços de coerentismo, não argumento que a coerência é primária, deixando-a como única fonte de justificação. Por si mesma, a justificação oferecida por coerência não é suficiente para justificar uma crença ao nível exigido para conhecimento, nem é necessária para o conhecimento, ao menos em contextos normais, não-céticos. Desejo argumentar apenas que para Reid, o valor da coerência não é simplesmente a ausência de anuladores [defeaters], isto é, o valor da consistência. Coerência tem valor epistêmico positivo e pode impulsionar, embora não suplante, a justificação das crenças (Poore, 2015, p.223, grifos meus).

Considero aqui sua ideia de que uma "justificação adicional" por meio da coerência do sistema de crenças. A princípio, essa interpretação parece não apresentar nenhuma dificuldade, uma vez que a coerência, como Poore a coloca, é apenas uma maneira de adicionar valor aos princípios primeiros que constituem o fundamento do conhecimento. Contudo, essa ideia, a meu ver, implica uma dificuldade. Essa é uma lição ensinada por Laurence Bonjour (1985) sobre as consequências de se apelar ao coerentismo no contexto do fundacionalismo:

A solução fundacionalista do tipo fraco para esse problema [regressão epistêmica] é tentar aumentar a justificação de crenças básicas e não-básicas apelando para o conceito de coerência. Grosso modo, se um sistema apropriadamente grande e adequadamente coerente puder ser construído, contendo uma proporção razoavelmente alta de crenças básicas inicialmente críveis, juntamente com crenças não-básicas, então afirma-se que a justificação de todas as crenças no sistema, básicas e não-básicas, pode aumentar até o ponto de ser adequada para o conhecimento, de modo que a obtenção de um grau de coerência suficientemente alto pode exigir a rejeição de algumas das crenças básicas (Bonjour, 1985, pp.28-29, grifos meus).

Supor que as crenças básicas precisam de algo mais do que elas mesmas - que elas podem ser impulsionadas pela coerência do sistema doxástico que elas produzem - é supor um tipo fraco de teoria fundacionalista da justificação epistêmica. Nessa versão fraca de fundacionalismo, a suposição de uma justificação adicional pode implicar a diminuição do valor epistêmico dos princípios primeiros do conhecimento. Isto é, os princípios primeiros do senso comum não seriam capazes de desempenhar o papel epistemológico que Reid acredita que eles desempenham: eles não seriam verdadeiros como o filósofo supõe.

Não acredito que Poore suponha que Reid mantém uma versão fraca de fundacionalismo. $\mathrm{O}$ autor claramente admite que o impulso epistêmico dado pela coerência não é necessário para a verdade dos princípios primeiros. Contudo, é preciso reconhecer algo estranho na suposição de uma justificação adicional: como entender que um princípio de conhecimento "autoevidente", imediatamente justificado, 
pode se tornar mais justificado do que ele é inicialmente? Como Reid entende os princípios primeiros, eles são princípios autoevidentes e supor que existem maneiras que os tornam mais justificados é supor que eles são na verdade "parcialmente autoevidentes". Como Reid explica, a proposição que expressa um princípio primeiro autoevidente "possui a luz da verdade em si mesma, e não tem ocasião para tomá-la de empréstimo de nenhuma outra” (Reid, 2002, p.452). A interpretação de Poore, se não diminui o valor epistêmico dos princípios primeiros e sua autoevidência, teria de explicar o que significa impulsionar a justificação de princípios autoevidentes. É verdade que em sua obra Reid apresenta alguns argumentos em favor da verdade dos princípios primeiros. Como o filósofo explica, em uma passagem já citada (Reid, 2002, p.41), os argumentos que compõem a defesa da verdade desses princípios não são senão "maneiras por meio das quais" sua evidência pode tornar-se mais aparente. Contudo, estou longe pensar que esses argumentos oferecem uma justificação adicional para os princípios primeiros. Os princípios primeiros do conhecimento são imediatamente justificados, eles são crenças autoevidentes. Portanto, por mais que possa ser sugerido que uma interpretação que conjugue fundacionalismo e coerentismo seja interessante no contexto da filosofia reidiana, parece-me que o texto do próprio filósofo não a permitiria.

Procuro mostrar acima os aspectos de cada uma das interpretações que sugerem que Reid não é um fundacionalista. No caso da interpretação antifundacionalista, o texto reidiano é muito claro sobre o objetivo do filósofo de ir além da descrição psicológica dos processos mentais de formação de crenças. Reid tem interesse pela questão da verdade das crenças do senso comum: elas são princípios verdadeiros de conhecimento, diferentemente do que Wolterstorff pretende sugerir. No caso da interpretação coerentista, do mesmo modo, além da base textual reduzida (três passagens apenas), Lehrer precisaria defender que Reid abandona a ideia de crenças básicas, o que contradiz claramente o texto reidiano, no qual se lê que os princípios primeiros do senso comum são o fundamento do conhecimento, são o fundamento sobre o qual o edifício do conhecimento é construído. Por fim, a implicação da leitura de Poore é que Reid defenderia uma forma fraca de fundacionalismo, o que implicaria reduzir o valor de verdade dos princípios primeiros do senso comum, algo que claramente não seria consistente com o texto reidiano. Ademais, a ideia de justificação adicional não parece coerente com a ideia de que os princípios primeiros do senso comum são autoevidentes: como é possível "tornar mais evidentes" princípios que são autoevidentes? 


\section{Referências}

Bonjour, L. (1985). The Structure of Empirical Knowledge. Cambridge, Massachusetts and London: Harvard University Press.

Brun-Rovet, E. (2002). Reid, Kant and the Philosophy of Mind. The Philosophical Quarterly, LII(209), 495-510. DOI: https://doi.org/10.1111/1467-9213.00282

Chisholm, R. (1964). The Myth of the Given. In: Philosophy. Roderick Chisholm et al. (eds.). Englewood Cliffs: Prentice Hall.

De Bary, P. (2002). Thomas Reid and Scepticism: His Reliabilist Response. London and New York: Routledge, pp. 235-244.

De Paul, M. (2011). Foundationalism. In: The Routledge Companion to Epistemology. Sven Bernecker e Duncan Pritchard (eds.). London / New York: Routledge.

Freitas, V. (2018). A ciência política em Thomas Reid. Analytica. XXII(1), 39-61.

Freitas, V. (2020). A resposta de Thomas Reid ao ceticismo. Síntese: Revista de Filosofia, XLVII(147), 23-44. DOI: https://doi.org/10.20911/21769389v47n147p23/2020

Freitas, V. (2020) A noção de 'senso comum' em Thomas Reid. Discurso. L(1), 219237. DOI: https://doi.org/10.11606/issn.2318-8863.discurso.2020.171580

Greco, J. (2004). Reid's Reply to the Skeptic. In: The Cambridge Companion to Thomas Reid. Terence Cuneo e Rene Woundenberg (eds.). Cambridge: Cambridge University Press.

Haack, S. (1993). Double-Aspect Foundherentism: A New Theory of Empirical Justification. Philosophy and Phenomenological Research, LIII(1), 113-128. DOI: https: //doi.org/10.2307/2108056

Haakonssen, K., Wood, P. (2015). Introduction. In: Thomas Reid on Society and Politics. Edinburgh: Edinburgh University Press.

Lehrer, K., Smith, J. (1985). Reid on Testimony and Perception. Canadian Journal of Philosophy. Volume suplementar XXI, 21-38.

DOI: https://doi.org/10.1080/00455091.1985.10715888

Lehrer, K. (1986). Reid on Consciousness. Reid Studies, I, pp. 1-9.

Lehrer, K. (1989). Thomas Reid. London e New York: Routledge.

Lehrer, K. (2013). Thomas Reid on Common Sense and Morals. The Journal of Scottish Philosophy. XI(2), pp. 109-130. DOI: https://doi.org/10.3366/jsp.2013.0052

Malherbe, M. (1991). Reid et la Possibilité d'une Philosophie du Sens Commun. Revue de Métaphysique et de Morale, 96e Année, número 4, 551-571.

Poore, G. (2015). Theism, Coherence, and Justification. In: Thomas Reid on Mind, Knowledge, and Value. Rebecca Copenhaver e Todd Buras (eds.). Oxford: Oxford University Press.

Redekop, B. (2001). Thomas Reid and the Problem of Induction: From Common Experience to Common Sense. Studies in History and Philosophy of Science, XXXIII, 35-57. DOI: https://doi.org/10.1016/S0039-3681(01)00022-X

Reid, T. (1997). Inquiry into the Human Mind on the Principles of Common Sense. Derek Brookes (ed.). Edinburgh: Edinburgh University Press. 
Reid, T. (2002). Essays on the Intellectual Powers of Man. Derek Brookes (ed.). Edinburgh: Edinburgh University Press.

Reid, T. (2010). Essays on the Active Powers of Man. Knud Haakonssen e James Harris (eds.). Edinburgh: Edinburgh University Press.

Reid, T. (2015). Thomas Reid on Society and Politics. Knud Haakonssen e Paul Wood (eds.). Edinburgh: Edinburgh University Press.

Stern, R. (2004). Coherence as a Test for Truth. Philosophy and Phenomenological Research, LXIX(2), 296-326. DOI: https://doi.org/10.1111/j.1933-1592.2004.tb00396.x Van Cleve, J. (2003). Lehrer, Reid, and the First of All Principles. In: The Epistemology of Keith Lehrer. Erik J. Olsson (ed.). New York: Springer.

Van Cleve, J. (2005). Why Coherence in not Enough: A Defense of Moderate Foudationalism. In: Contemporary Debates in Epistemology. Mathias Steup e Ernest Sosa (eds.). Wiley-Blackwell, pp. 168-180.

Wolterstorff, N. (2001). Thomas Reid and the Story of Epistemology. New York, Cambridge University Press.

Esta obra está licenciada com uma Licença Creative Commons Atribuição-NãoComercial-

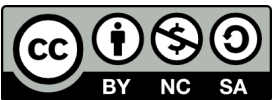

